\title{
A Multipath Model of Salesperson Performance in the Financial Services Industry
}

\section{Introduction}

The importance of customer orientation has been established beyond doubt both at the level of the firm and the individual sales person (Hartline et al., 2000; Narver and Slater, 1990; Singh and Ranchhod, 2004; Donavan et al., 2004; Tse et al., 2003). At the firm level, customer orientation combined with competitor orientation defines primarily a firm's market orientation (Kohli and Jaworski, 1990; Kirca et al., 2005; Narver and Slater, 1990; Langerak, 2003; Sandvik and Sandvik, 2003; Rapp et al., 2008). However, in a personal selling context, the customer orientation of the firm is manifested through the customer orientation of the sales persons representing the firm. Several studies have considered the positive effect of sales person's customer orientation on sales performance (Saxe and Weitz, 1982; Brown et al., 2002; McIntyre et al., 2000; Harris et al., 2005). These results largely reflect the conventional wisdom which places due emphasis on the central role of the boundary spanners (ie. sales people) in providing added value in the exchange process and forge long term relationship with customers (Leigh et al., 2001; Beverland, 2001).

Sales person's customer orientation is particularly significant in the case of the financial services industry, the specific context used for this study, where due to the multiplicity and the complex nature of products and services create situations where customers depend on sales person's advice while making investment decisions.

However, despite the significance of salesperson customer orientation and its impact on long term organisational performance (Saxe and Weitz, 1982; Boles et al., 2001; Brown et al., 2002), customer orientation is not always desirable. According to Franke and Park (2006; p: 694) "the benefits of customer-oriented selling must be weighed against its costs, such as the 
salesperson's time spent identifying customer problems and solutions, possibly reduced margins or increased service costs entailed in satisfying customers, and lost sales that might have been made with more aggressive sales approaches". Sales persons are also often trapped into sales situations where customer orientation is not perceived to be desirable or encouraged. For instance, in situations where the firm lacks a customer driven culture; or if there are constraints imposed by the competitive situation then selling orientation is often the preferred choice compared to a customer orientation (Saxe and Weitz, 1982; Thakor and Joshi 2005). Declining role of sales people in a highly centralized technology oriented sales environment, closely monitored with sales targets and performance (Brooks, 2004; Weeks, 2000; Van der Voet, 2013) also leads to an uneven adoption of customer orientation in sales force.

Sales person customer orientation is a research topic that has seen more than three decades of research (for a review please see Schwepker, 2003). However, the practical importance of this topic as well as the plethora of interesting theoretical issues that it raises continue to attract significant research attention even today.

An important stream of research involves investigating the antecedents of sales person customer orientation. Exploring the antecedents is particularly important as it helps in providing insights to practitioners for developing customer orientation in their sales force. A multitude of antecedents have been identified. These antecedents can broadly be divided into three (i) organisation related factors like culture, supervisor support (eg. Boles et al, 2001; Flaherty et al, 1999; Honeycutt et al, 1995 etc.) (ii) Job related factors like job satisfaction and role stress (Hoffman and Ingram, 1991; Bettencourt and Brown, 2003) or (3) Personality trait related factors like agreeability and need for activity (Brown et al 2002). 
However, an important issue that constraints many of these studies is the lack of integration due to a narrow focus. As Zablah et al, (2012) points out, for achieving parsimony most of the studies that deal with customer orientation at the personnel level miss out on 'common antecedents that is the antecedents that may have an impact on both customer orientation and its consequences - which lead to inconsistent or unexplained results. To address the call for greater depth and integration in exploring the impact of customer orientation made by studies like Zablah et al (2012) and Crawford et al, (2010) we attempt to develop a multi-path model that links organisational, job related and personality related factors to customer orientation and to sales performance. The study thus contributes to the existing literature through bringing together three different streams of antecedents to salesperson customer orientation through a multi-path model. Though lacking parsimony, such a model is important as it addresses some of the main shortcomings of the existing models.

Another important issue seldom considered while making generalisations about empirical results is that most of the extent studies on sales people customer orientation were carried out in developed countries. Unlike in emerging markets in the mature and saturated markets of developed countries, effective institutional mechanisms and sophisticated marketing practices enable salespersons to adopt customer orientation very successfully. In the emerging markets like India, the market dynamics may vastly differ. Even the degree of market orientation practiced by the firms in the emerging markets may vary compared to those practiced in the developed countries (Anwar and Sohail, 2003) and this may reflect in the sales person's customer orientation as well. This aspect could be particularly relevant in the financial service industry in the emerging markets like India, which is undergoing a state of flux due to changing regulation and structural and technological factors (Padmavathy, Balaji and Sivakumar, 2012). The resultant market dynamics, 
disintermediation and high degree of competition, makes it an important context to investigate the role of customer orientation and related factors on the sales-force performance.

A model that brings together the multitude of factors that impact customer orientation and sales performance therefore has the potential to contribute to the knowledge on adoption of customer orientation. To the best of our knowledge studies in salesperson customer orientation have rarely investigated a combination of antecedent constructs that relate to a sales person's organisation, job as well as personality. The objective of the study is therefore to propose and empirically analyse a conceptual framework that considers key organisational, job and personality related variables along with sales person's customer orientation $(\mathrm{SCO})$ as antecedents to sales performance in the financial service industry. We also explore the mediating role of SCO in the impact of these key antecedents on the sales performance.

In the following sections, we develop the conceptual framework and describe the context of our empirical study. The analysis results and the interpretations are explained subsequently.

\section{Conceptual Framework}

Customer orientation has been defined as an employee attitude (Stock and Hoyer, 2005) as well as a surface trait (Harris, Mowen and Brown, 2005; Brown et al, 2002). The conceptual model is developed based on Bagozzi's (1992) appraisal - response - behaviour theory as well as the model of the hierarchical effects of personality on Behaviour (Allport, 1961; Mowen and Spears, 1999). Bagozzi's (1992) theory posits that individuals make appraisals of their context which lead to an emotional response which then results in their behaviour. The hierarchical model of personality traits on behaviour posits the impact of basic traits of an individual on surface traits like customer orientation and then onwards to behaviour. In this study we argue that 
organisational and job characteristics such as organisational competitor orientation, centralisation, supportive work environment, organisational identification, job satisfaction etc. are subjected to close appraisal by sales persons in the financial sector which lead to higher levels of customer orientation which we posit as an attitudinal response. Customer orientation then leads to behaviour that results in higher levels of performance. Further, based on the idea of customer orientation as a surface trait, we use the hierarchical effects of personality to posit customer orientation as surface trait determined by the sales person's basic traits. Both Bagozzi's (1992) theory and the hierarchical effects of personality on behaviour have been used extensively in the extant literature on sales management (eg. Schmit and Allscheid, 1995; Testa, 2001; Yee, Yeung and Cheng, 2008 etc.). In the subsequent sections we develop the conceptual model through a review of the relevant literature.

\section{Customer Orientation and Sales Performance}

Prior studies have concluded that a customer oriented selling approach is important from the perspectives of a salesperson, organisation and customer (Dunlap et.al., 1988; Goff et.al., 1997). In fact, even as early as in their pioneering study on salesperson customer orientation, Saxe and Weitz, (1982) provide evidence of positive association between customer-oriented sales behaviour and sales performance by the salespeople. The same relationship was observed by studies in numerous other sales contexts (eg. Swenson and Herche, 1994; Dunlap et al., 1998 etc.). Sales performance have been found to be a natural consequence of customer orientation in these studies and thus it has been argued that, for organisations, who aim at improving sales performance, customer orientation of its salespersons is absolutely important. Hence, we hypothesise that: 


\section{H1: Salesperson's customer orientation (SCO) has a positive influence on individual sales performance (SP).}

While customer orientation of the salesperson influences performance, this relationship is in turn the final outcome of several antecedent factors. In order to develop a deeper understanding of this mechanism, it is necessary to identify and bring together these antecedent variables. As explained above, these antecedent factors straddle organisational, job related and personality related domains.

Customer-oriented selling is more likely to happen when salespeople have the expertise necessary to assist the customers. It could be argued that the practice of customer-oriented sales techniques is a long-term strategy that is accompanied by some level of risk (Saxe and Weitz, 1982). This risk is associated with the fact that salespeople engaging in customer-oriented selling are likely to make shortterm sacrifices in their current sales results like explaining both the positive and negative aspects of the product that they sell (Schwepker, 2003). Consequently, it is reasonable to assume that only confident and competent salespeople would have either the predisposition or the ability to engage in this risky practice. Sales-person customer orientation is therefore the outcome of a set of antecedent conditions, that are extremely critical in determining both the level of adoption of customer orientation as well as the sales performance of the salespersons. We therefore focus on the possible antecedent conditions to develop the comprehensive conceptual model. The model is shown in fig.1

Take in fig. 1 here

\section{Mediating Role of Customer Orientation}


As can be seen from this model, we position customer orientation as the central mediating variable that link the range of antecedent factors to sales performance. Our conceptualisation reflect extant literature where customer orientation is often positioned as an intermediate variable that mediates the link between several antecedent conditions and sales performance (eg. Boles et al, 2001; Franke and Park, 2006; Zablag et al, 2012; Lussier and Hartmann, 2016). In this study, based on Bagozzi’s (1992) theory, we posit that employees first make an appraisal of the organisational and job related conditions, which then shape their level of customer orientation and subsequently their performance. Hence customer orientation acts as the main mediating factor in this mechanism.

\section{Organisation Related Antecedents of Customer Orientation}

Organisational related factors have been posited as influencing both customer orientation as well sales performance of an individual sales person. We consider four important factors in this context: (i) organisation's customer orientation (ii) level of centralisation within the organisation (iii) competitive orientation of the organisation and (iv) supportive work environment of the organisation.

\section{Organisational Customer Orientation and Competitor Orientation}

Organisational customer orientation and competitor orientation are considered as reflections of an organisation's level of market orientation (Grinstein, 2008). Siguaw et al (1994) looked at the impact of market orientation of a firm on the level of customer orientation of its salespersons and

found a significant positive relationship. A similar result was derived by Jones et al (2003). A customer and competitor oriented organisation will foster an internal climate that can be expected to influence the salespeople in the organisation to be more customer-oriented and it is likely that 
sales people with higher levels of customer orientation tend to achieve high levels of performance with respect to sales (Harris et al., 2005). Firm's dedication to build and maintain a concern for the customers will be reflected in the way salespeople interact with the customers. Thus, positive association is expected between the firm's customer orientation, competitive orientation and a salesperson's customer orientation which will in turn lead to better performance (Kulp et al., 2004).

H2: Organisational customer orientation (OCO) has a positive influence on individual sales person customer orientation in such a way that $(\mathrm{SCO})$ mediates the relationship between OCO and $S P$

H3: Organisational competitive orientation (OC) has a positive influence on SCO such that $S C O$ mediates the relationship between $O C$ and $S P$

\section{Centralisation}

The delegation of decision making authority and participation by organisational members in the decision making process have significant influence on market orientation (Kohli et al., 1993). A highly centralized organisational environment can lead to inflexibility and employees who work in such a culture will perceive it to be difficult to adopt a customer oriented attitude. This aspect has been highlighted by Lancaster and Velden (2004) through their action research study in a bank. Similarly, McClure (2010) showed that a bureaucratic culture which is closely associated with centralisation hampers the adoption of marketing orientation significantly. Lack of flexibility experienced by the sales people would force them to be less customer-oriented and would be less likely to work with customer's best interest in mind. Hence: 
H4: Degree of centralisation of the organisation $(\mathrm{OZ})$ has a negative influence on salesperson $S C O$ such that SCO mediates the negative relationship between $O Z$ and SP

Supportive Work Environment

In the same way, a supportive work environment can substantially reduce the employees' role stress and improve the performance levels (Babin et al., 1996). When the employees feel valued in an organisation they would be inclined to extending the same to their co-workers and support them in their job related endeavours (Eder et al., 2008). A supportive work environment is one in which employees would be motivated to work towards addressing customer needs in a satisfying manner which would automatically achieve the long term organisational goal (Boles et al, 2001). Further, based on Bagozzi's (1992) theory, a supportive work environment will be appraised by the employee to be one where there is no risk in taking a long-term orientation to selling, thus fostering a customer oriented attitude. When employees feel valued in a firm it would result in improved performance both at individual and organisational levels. So it is argues that:-

H5: A Supportive Work Environment (SWE) has a positive effect on SCO such that SCO mediates the relationship between $S W E$ and $S P$

\section{Job Related Factors}

Sales performance is impacted by a host of job related factors. We consider three factors in our conceptual model: (i) experienced meaningfulness, (ii) pay related satisfaction and (iii) organisational identification of the sales person.

Experienced Meaningfulness 
Experienced meaningfulness is a key determinant of activity importance (Thakor and Joshi, 2005).

Experienced meaningfulness helps salespersons to account for the tasks carried out as part of the routine sales job within his or her own system of values. Experienced meaningfulness also has the potential to generate a feeling of accomplishment in a salesperson is he/she is successful in engaging in customer-oriented selling (Thakor and Joshi 2005). Experienced meaningfulness improves the perception of significance of the work-related activities by aligning the same with the value system of the salesperson (Hackman et al., 1980). Previous studies have found a direct link between experienced meaningfulness and customer orientation as experienced meaningfulness helps salespersons to justify the extra effort required to demonstrate customer orientation in a particular selling context (Thakor and Joshi, 2005). Hence:

H6: Experienced Meaningfulness (EM) has a positive relationship with SCO such that SCO mediates the relationship between $E M$ and $S P$

\section{Organisational Identification}

Organisational identification can be understood as a state of psychological congruence between the values of salesperson and organisation (Mael et al., 1992). Employees would be interested to assign more time and efforts to deal with their job challenges innovatively if there is an alignment of their self-interests with the interests of the organisation that they are employed with (Hirst et al., 2009;

Madjar et al., 2011). Salespersons who have high level of organisational identification, will be highly committed to the organisation and hence will be willing to expend the extra effort to demonstrate customer orientation which will then lead to better performance. Hence:

H7: Organisational Identification (OI) of the sales persons have a positive influence on SCO such that SCO mediates the relationship between $\mathrm{OI}$ and SP

Pay related satisfaction 
According to Oliver and Anderson (1994), salary is positively related to job performance, but researchers have also established that there is no significant relationship among compensation and performance (Babakus et. al., 1996; Piercy et al., 1998). The relationship between jobsatisfaction especially pay satisfaction and customer orientation has not been very clear (Shwepker, 2002). While previous studies have shown that there is a positive association between them (Hoffman and Ingram, 1991, Siguaw et al, 1994), the direction of causality is not very clear. In this study we argue based on Bagozzi's(1992) theory that salespersons who are satisfied by their pay, make a positive appraisal of their job, which helps them to be more long term oriented and inclined to take risks associated with a customer orientation. Thus, pay satisfaction will positively lead to customer oriented attitudes which in turn leads to better sales performance.

H8: Pay Satisfaction of the sales person (PS) has a positive influence on SCO such that SCO mediates the relationship between PS and SP

\section{Personality-related Factors}

Personality related factors represented through the big-five personality traits has been shown to have a direct relationship to job performance in several studies (for a meta-analysis please see Hurtz and Donovan, 2000). According to Brown et al (2002), personality traits can be considered as basic traits of an individual which does not change according to different contexts. Surface traits often have direct relationships to performance (Brown et al, 2002). Of the personality traits, conscientiousness, emotional stability and agreeability have been found to have a positive linkage to job performance in past studies. (Barrick, Mount and Judge, 2001; Hurtz and Donovan, 2000; Salgado, 1997). Need for activity has been identified as a separate personality trait by Buss (1988) 
and is defined in terms of the variation in activity levels of individuals. The need for activity trait is however not part of the original big-five personality trait. However, given the activity seeking behaviour underlying this trait, it is conceivable that this trait can lead to better job performance. According to Brown et al (2002, p.113), individuals "with a high need for activity will tend to complete more tasks and do more things in everyday life". It is thus hypothesised that sales persons with high need for activity trait will also perform well in their job.

Customer orientation of the sales person has been understood as an emotional investment that propels salespeople to higher levels of performance (Brown et al., 1997). It is revealed through research that customer orientation which is identified as a learned behaviour could be impacted by environmental factors which would direct behavioural adaptations (William et al., 1990). Few studies had attempted to understand the relationship between personality factors and customer orientation of the employees. A possible connection between the individual's customer orientation and personality characteristics has been examined by researchers (Brown et al. 2002; Widmier, 2002). These indications bring out the importance of relationship between personality factors and customer orientation of the employees while attempting to understand the performance implications.

To understand the role of customer orientation in the relationship between personality factors and performance with respect to performance ratings of salespeople and supervisors, Brown et.al. (2002) came with the hierarchy model. The model incorporates basic personality factors (i.e., introversion, emotional stability, conscientiousness, agreeability, openness to experience, and need for activity), customer orientation as a mediator, and performance ratings as the final outcome. The study found that not all six of the personality factors, affected customer orientation. The 
research also established that the hierarchical model enhanced the predictive power of personality factors on performance ratings, especially for self-rated performance. So we propose that:-

H9: Agreeability of the Salesperson (PAB) has a positive influence on SCO such that SCO mediates the relationship between PAB and SP

H10: Conscientiousness of the salesperson (PCON) has a positive influence on SCO such that SCO mediates the relationship between PCON and SP

H11: Need for Activity of the salesperson (PNA) has a positive influence on CO such that CO mediates the relationship between PNA and SP

H12: Salesperson instability (PNI) has a negative influence on SCO such that SCO mediates the relationship between $P N I$ and $S P$

Putting it all together, Figure 1 presents an operational model that includes the antecedents and the consequences of a salesperson's customer orientation, reflecting the hypotheses developed in the preceding sections. Thus, the general hypothesis of the study may be presented as follows:

“Salesperson's customer orientation mediates the relationships between (a) Organisation factors (e.g., Organisational customer orientation, Organisational competitive orientation, Centralisation, Supportive work environment), (b) Job factors (e.g., Extended meaningfulness, Organisational identification, Pay satisfaction), and (c) Personality factors (e.g., Instability, Agreeability, Conscientiousness, Need for activity), and Sales performance”.

Take in fig. 1 here

\section{Empirical Study}

For the study, sales people (both male and female) working for insurance companies and Banks (both public and private) with two years of sales experience of which one year with the present 
organisation, in the state of Kerala, India were considered. The questionnaires were distributed to 1500 insurance salespeople and 750 salespeople from the banking industry across the five chosen districts in the state of Kerala. The salespeople were contacted in their branches when they were attending their monthly review meetings after obtaining permissions from the branches. The purpose of the data collection and the method of filling up of the questionnaires were explained and their doubts/clarifications were addressed. Repeat visits were necessary for obtaining the filled up questionnaires. Sample control measures like collection of data from not more than two branches in a day and meeting the respondents at different time were employed to increase the accuracy of the data. Once the data collection from each branch was completed the reporting authorities of the salespeople (Team leaders, Development officers and Asst. Managers) were contacted to verify the accuracy of the sales performance details provided by the employees. This exercise was meant to eliminate careless answers as two of the items in the sales performance questionnaire involved asking the respondents about their performance in selling new products as well as the full portfolio of products. Line-managers were contacted to verify about subordinates who were qualified to answer both the questions. Based on the evaluations of the supervisors, a total of 87 responses were eliminated from the final data set. The actual scores were kept confidential. This procedure helped to reduce the self-reporting bias of respondents. A total of 1437 filled up responses were obtained of which 331 responses (244 incomplete responses and 87 responses suggested by the supervisors) were omitted. Finally, 1106 usable responses were obtained and used for the study and the data collection was completed within a span of 7 months.

A total of 1106 responses 622 respondents or (56\%) were males and the remaining females. In terms of the age profile, 407 respondents were in the age group of 25 to 34 yrs (36.8\%), 311 in the age group 35 to 44 yrs (28.1\%), 296 between 45 to 54 yrs (26.8\%) and 92 respondents were over 
$55 \mathrm{yrs}(8.4 \%)$. Regarding the sales experience of the respondents, 416 people were having a sales experience of 2 to $5 \mathrm{yrs}(37.6 \%), 348$ people with 6 to $10 \mathrm{yrs}(31.5 \%), 155$ people with 11 to 15 yrs $(14 \%)$ and 187 people with more than 15 yrs of sales experience. When the current tenure of the respondents was analyzed it was observed that 393 people had been working in the current organization for 1 to 3 yrs (35.5\%), 382 people were having experience in the present organization for 4 to 8 yrs $(34.5 \%)$ and 133 with experience ranging from 8 to 12 yrs (12\%) and 198 people were there with the current organization for more than 12yrs (17.9\%). The demographic classification of the data is summarized in table below.

\section{Measures}

The constructs were measured using multi-item scales adapted from the literature and were measured on a seven point likert scale. Both Organisation's customer orientation (OCO) (six item scale) and Organisation's competitive orientation (OC) (four item scale) was adapted from Narver and Slater (1990). Organisation's centralisation of authority was measured using a four item scale by Jaworski and Kohli,(1993) and Supportive work environment with a four item scale from Moos (1991). The perception of the job is captured with the constructs experienced meaningfulness of the job (EM), organisational identification (OI) and pay satisfaction (PS). Personality of the salesperson is captured by adapting questions from five factor model (FFM) inventory. The scales for these constructs are adapted from the following: Experienced meaningfulness, a six item scale from Williams (1988); organisational identification (seven item scale) from Porter et al., (1974) ; pay satisfaction using a five item scale from Comer et al., (1989) ; and Personality dimensions (Instability, Agreeability, Need for activity and Conscientiousness) were measured using sixteen item scale from Brown et al., (2002). Finally Salesperson's customer orientation was measured using a twelve item scale by Saxe and Weitz, (1982) and sales performance with a the 
five item scale by Boles et al.,(2001). The means, standard deviations and the bi-variate correlations of the measures are given in table. 1.

Take in table. 1 here

\section{Results and Analysis}

To analyse the causal relationships between constructs used in the study, the structural equation modelling (SEM) approach was adopted. Analysis of the research model was done using the Partial Least Square (PLS) based software, Warp PLS 5.0. The choice of Partial Least Square Analysis was justified on two counts. The first was that PLS can accommodate both reflective and formative scales easily, compared to covariance structure analysis. The second aspect was that PLS does not require any a priori distributional assumptions and a relatively small sample size is acceptable (Chin, Marcolin, and Newsted, 2003). The PLS regression algorithm with boot strapping method of re-sampling was used for estimation of the model that maximizes the variance explained in the latent variable scores by the latent variable indicators. The estimates included path coefficients with 'p' values, indicators' weights, loadings, and factor scores.

\section{Validation of Measures}

The validity of the model was evaluated with various fit indices. In addition, it was recommended that the average variance inflation factor (AVIF) be lower than 5 (Kock, 2010). The details of considerations regarding validity and reliability are provided in table (2).

Take in table. 2 here 
It was found that all three fit criteria were met and the model had an acceptable predictive and explanatory quality as the data were well represented by the model. All the factor loadings of the reflective indicators were found to be more than 0.5 with ' $\mathrm{p}$ ' $<0.01$. The composite reliability, Cronbach alpha and average variance extracted (AVE) were above the threshold limits. The model emerged as one with satisfactory value for R-squared and Q-squared being indicators for predictive validity. The square root of AVE for all constructs was found to be more than any of the correlations involving that latent variable. All these observations confirmed the reliability and validity of the constructs making it suitable to draw conclusions on causality.

Harman's single-factor test was conducted to test the presence of common method effect. In the Common Method Variance Bias test carried out for the data set used for the analysis by the researcher, the test has obtained a value of $22.295 \%$ for its single factor extraction sum of squared loadings. This value being less than 50\%, establishes that there is no Common Method Variance Bias existing with the data set that the researcher has used for the analysis purpose. The reliability and validity tests of the data were also performed and the results were all within the acceptable range.

\section{Validation of the Conceptual Model}

To test the mediation hypotheses we used the Sobel's test to test the significance of the direct effect of the independent variable compared to its indirect effect. Two models were run: one with all the independent variables linked through SCO to SP - Model (1) and the second where the independent variables linked directly to SP - Model (2). The figures 3 and 4 shows the two models with and without the mediation effects respectively. If there is a significant reduction in the path coefficient of the independent variable to the dependent variable in model (2) compared to model (1), we can infer a mediation effect for customer orientation. Subsequently, we checked the level 
of significance of the path coefficient from the independent variable on the dependent variable in model (1). A significant coeffect would imply a partial mediation effect while a non-significant coeffect would imply a full mediation.

The coefficients generated from the two models were first tested using the Sobel's test to see whether the mediation was significant and then the coefficients of the independent variable with Sales Performance were compared between the models in order to assess partial or full mediation. First, the direct path from SCO to SP was found to be positive and significant and hence H1 was supported.

When we consider the mediation effects, except for Pay satisfaction and Need for activity, all the antecedent variables were significantly related to Customer Orientation (please see fig.3). This in itself is a significant contribution as it points to a multiplicity of antecedents to customer orientation. Previous studies have often limited their scope while exploring the antecedents of customer orientation. Hence the results from the study point to the possibility that in previous studies CO could have been impacted by a multiplicity of factors which were not included. This study therefore points to the need for expanding the domain of antecedent variables for customer orientation. The impact of personality traits like instability, agreeability and conscientiousness on customer orientation are quite significant as this address the call by previous studies for exploring personality traits as antecedents of customer orientation.

Similarly, except for organisational customer orientation, pay satisfaction and conscientiousness, all the antecedents are either directly or indirectly related to sales performance. This is again important as this point towards the variety of factors that influences the performance of sales personnel. From the Sobel test coefficients, we find that in the case of organisational customer 
orientation, competitor orientation and centralisation, there is no mediation effect of salesperson customer orientation as the Sobel test coefficient is not significant. Though the direct relationship of competitor orientation on sales performance without $\mathrm{SCO}$ is found to be significant. Regarding supportive work environment, partial mediation is supported at $\mathrm{p}<0.1$ level (Sobel's test coefficient 1.65). This is an important result as it shows that supportive work environment influences sales performance initially by impacting the customer orientation of the salesperson and then onwards to impacting the sales performance.

Of the job-related constructs, Sobel's test show that the impact of experienced meaningfulness on sales performance is found to be mediated by customer orientation of the salesperson albeit partially (Sobel's test statistic 3.00; $\mathrm{p}<0.01$ ). Thus, experienced meaningfulness initially leads to customer orientation and then onwards to sales performance, although a direct impact on sales performance is also found to be possible. Sobel's test also support the mediating effect of customer orientation in the case of organisational identification (Sobel's test statistic 4.14, $\mathrm{p}<0.01$ ). Sales person's organisational identification is thus found to lead to customer orientation and then onwards to sales performance. This effect is important as the results point towards a full mediation. Customer orientation is not found to have any mediating impact in the relationship between Pay satisfaction and sales performance. In fact, Pay satisfaction is not seen to have any direct or indirect impact on sales performance.

As far as personality variables are concerned, Need for activity and Conscientiousness are not found to be mediated by customer orientation. While need for activity is seen to positively influence sales performance, it is not seen to be impacting customer orientation. Similarly, Conscientiousness is seen to impact customer orientation but not sales performance. However, in the case of sales person agreeableness, customer orientation is seen to mediate its relationship to 
sales performance with a partial mediation effect (Sobel's test static 3.2, $\mathrm{p}<0.01$ ). In the case of instability, there is again a partial mediating impact with the negative impact of instability on sales performance reduced by the effect of customer orientation (Sobel's test statistic $-1.71 ; \mathrm{p}<0.1$ ).

Take in fig. 3 , fig.4 here

\section{Discussion}

The study attempted to understand various influences and their implications on customer orientation of salesperson and on sales performance in the financial services sector. Three important groups of influences namely, organisational, job and personality factors were considered for the study. Thus, the study attempted to bring together a host of concepts and develop a multipath model of customer orientation and sales performance.

First of all, the mediation effect of Customer orientation is pronounced only in the case of Supportive work environment, Organisational Identification, Experienced Meaningfulness, Personal Agreeableness and Personal instability. Of these only in the case of OI a full mediation is found, in all the other cases it is a case of partial mediation. A mediating effect (partial or full) would imply that these variables exert an indirect impact on sales performance through customer orientation. In fact, this in turn implies that some of the positive impact they exert on customer orientation is in fact translated by customer orientation in improving sales performance. This is an important insight that helps to understand the contours of the impact of customer orientation on sales performance; thereby partly addressing the concerns raised by Zablah (2012).

The empirical study brings out some important results. As (Boles et al, 2001) suggests, centralisation of authority is found to have negative influence on customer orientation of the 
employees, however, centralisation has a positive indirect effect on sales performance as well as an insignificant direct effect. This is a counter intuitive effect due to the presence of a significant indirect effect but an insignificant direct effect. This needs further probing. Similarly, lack of any direct or indirect influence of organisational level customer orientation on sales performance of the sales person is quite contrary to the extant literature (eg. Siguaw et al, 1994).

Organisational competitive orientation on the other hand has a direct significant effect on sales performance, but no indirect effect. This is quite understandable as competitor orientation helps to improve the performance of a sales person quite independent of customer orientation. Supportive work environment fosters improved relations among employees and helps individuals to perform better in their job. When the organisational goals and the individual goals are aligned optimally, improved performance outcomes of an employee would be valued more by the organisation as it is the desired goal of the organisation also. Employees will experience a feeling of importance in the organisation under such circumstances which would help them to perceive their job as more meaningful.

An important result pertains to that of organisational identification and experience meaningfulness. Both the variables are mediated by customer orientation in their effect on sales performance. These two variables enhance customer orientation and then influence sales performance entirely through their effect on customer orientation. Both these variables are deeply associated with value congruence between the sales person and the organisation and hence their influence on customer orientation could be due to their deep felt commitment to the cause of the organisation.

The personality influences on sales performance and that of customer orientation indicate that there is strong influence of agreeability and conscientiousness on sales person's customer orientation 
and sales performance. Though studies have indicated negative association of instability with sales performance, this study found a positive association between the same though instability has a negative impact on customer orientation. When salespeople face hindrances in helping customers find solutions for their problems, they would feel irritated, tensed and might even be depressed. This study urges to understand emotional instability in a financial services sales situation, as the outcome of an unpredictable desire of a salesperson to serve customers and fulfil their needs. The discrepancy of emotion may be linked with weakened ability to serve customers well. When emotional stability is understood in this context, the positive association it has with individual performance can be justified. The study highlights the importance of agreeability factor for a salesperson, especially in the financial services industry. In a relationship building context, employees possessing more agreeability factors, tend to perform better. This study sketches the key influences on the customer orientation of the salesperson and on his/her performance. The role of customer orientation of the salespeople in the relationship building context is evidently brought out through this study. Mangers should focus on developing and fostering customer orientation in the salespeople who are entrusted with building and maintaining long lasting relationships with their customers. It is anticipated that the integrated model would help mangers in addressing these challenges effectively.

\section{Conclusion}

The study provides a multi-path approach to understand the antecedents of sales person customer orientation. The results from the empirical study, helps to develop a better understanding of how a multiple set of factors jointly influences customer orientation. Several interesting results were thrown up in the analysis. The study provides several interesting ideas for future research. First of all, the multi-path approach supports the logic of considering a comprehensive set of variables 
simultaneously to understand important constructs like customer orientation. Such an approach provides better validity as issues of multiple influences and joint influences can be better represented. Second, some of the counter intuitive results pertaining to variables like centralisation and organisational competitor orientation should be probed further. The present study throws open existing beliefs about how these variables impact customer orientation.

Finally, the study also supports greater research on the real influence of personality variables on customer orientation. This stream is still not fully developed.

The study is not devoid of limitations. The problems of generalisation of a convenience sample being the most important limitation. Further the scales used for measuring the constructs were originally conceived in western countries and hence need to be interpreted with caution when applied to a different culture. 


\section{References:}

Allport, G. W. (1961). Pattern and growth in personality.

Aziz Anwar, S., and Sadiq Sohail, M. (2003). Testing market orientation of bank managers in the emerging economy of Brunei. International Journal of Bank Marketing, 21(6/7), 289-295.

Babakus, E., Cravens, D. W., Grant, K., Ingram, T. N., and LaForge, R. W. (1996). Investigating the relationships among sales, management control, sales territory design, salesperson performance, and sales organisation effectiveness. International Journal of Research in Marketing, 13(4), 345-363.

Babin, B. J., and Boles, J. S. (1996). The Effects of Perceived Co-worker Involvement and Supervisor Support on Service Provider Role Stress, Performance and Job Satisfaction. Journal of Retailing, 72(1), 57-76.

Bagozzi, R.P.(1992). "The Self-Regulation of Attitudes, Intentions, and Behavior," Social Psychology Quarterly, 55 : 178 -204

Barrick, M. R., and Mount, M. K. (1991). The big five personality dimensions and job performance: a meta-analysis. Personnel psychology, 44(1), 1-26.

Barrick, M. R., Mount, M. K., and Judge, T. A. (2001). Personality and performance at the beginning of the new millennium: What do we know and where do we go next? International Journal of Selection and Assessment, Vol.9, 9 - 30.

Bettencourt, L. A., and Brown, S. W. (2003). Role stressors and customer-oriented boundary-spanning behaviors in service organisations. Journal of the academy of Marketing Science, 31(4), 394-408.

Beverland, M. (2001). Contextual influences and the adoption and practice of relationship selling in a business-to-business setting: an exploratory study. Journal of Personal Selling and Sales Management, 21(3), 207-215.

Boles J. S, Babin B. J, Brashear T. G and Brooks C (2001). An examination of the relationship between retail work environments, salesperson selling orientation-customer orientation and job performance. Journal of Marketing Theory and Practice 9(summer):1-13.

Brown, T., Mowen, J., Donovan, D. T., and Licata (2002). The customer orientation of service workers: Personality trait determinants and effect on self-and supervisor performance ratings. Journal of Marketing Research, 39(2), 110- 119.

Camarero, C. (2007). Relationship orientation or service quality? What is the trigger of performance in financial and insurance services?. International Journal of Bank Marketing, 25(6), 406-426. 
Crawford, E. R., Jefferey, A. L and Bruce L. R (2010), "Linking Job Demands and Resources to Employee Engagement and Burnout: A Theoretical Extension and MetaAnalytic Test," Journal of Applied Psychology, 95 (5), 834-48.

Donavan, D. T., Brown, T. J., and Mowen, J. C. (2004). Internal benefits of service-worker customer orientation: Job satisfaction, commitment, and organisational citizenship behaviors. Journal of marketing, 68(1), 128-146.

Dunlap, B.J., Michael J. Dotson, andTerry M. Chambers (1988), "Perceptions of Real-Estate Brokers and Buyers: A Sales- Orientation, Customer-Orientation Approach," Journal of Business Research, 17 (September), 175-187.

Eder, P., andEisenberger, R. (2008). Perceived organisational support: Reducing the negative influence of coworker withdrawal behavior. Journal of Management, 34(1), 55-68.

Flaherty, T. B., Dahlstrom, R., and Skinner, S. J. (1999). Organisational values and role stress as determinants of customer-oriented selling performance. Journal of Personal Selling and Sales Management, 19(2), 1-18.

Franke, G. R., and Park, J. E. (2006). Salesperson adaptive selling behavior and customer orientation: a meta-analysis. Journal of Marketing Research, 43(4), 693-702.

Goff, B. G., Boles, J. S., Bellenger, D. N., andStojack, C. (1997). The influence of salesperson selling behaviors on customer satisfaction with products. Journal of retailing, 73(2), 171-183

Grinstein, A. (2008). The effect of market orientation and its components on innovation consequences: a meta-analysis. Journal of the Academy of Marketing Science, 36(2), 166-173.

Hackman and Oldham, G R (1980). Work design. Reading MA: Addison-Wesley.

Harris, E. G., Mowen, J. C., and Brown, T. J. (2005). Re-examining salesperson goal orientations: personality influencers, customer orientation, and work satisfaction. Journal of the Academy of Marketing Science, 33(1), 19-35.

Hartline, M.D., Maxham, J.G. III and McKee, D.O. (2000), "Corridors of influence in the dissemination of customer-oriented strategy to customer contact service employees", Journal of Marketing, Vol. 64, pp. 35-50.

Hirst, G., Van Knippenberg, D., and Zhou, J. (2009). A cross-level perspective on employee creativity: Goal orientation, team learning behavior, and individual creativity. Academy of management journal, 52(2), 280-293.

Hoffman, K. D., and Ingram, T. N. (1991). Creating customer-oriented employees: The case in home health care. Marketing Health Services, 11(2), 24. 
Honeycutt, E. D., Siguaw, J. A., and Hunt, T. G. (1995). Business ethics and job-related constructs: A cross-cultural comparison of automotive salespeople. Journal of Business Ethics, 14(3), 235-248.

Hurtz, G. M., and Donovan, J. J. (2000). Personality and job performance: the Big Five revisited. Journal of applied psychology, 85(6), 869.

Jones, E., Busch, P., and Dacin, P. (2003). Firm market orientation and salesperson customer orientation: Interpersonal and intrapersonal influences on customer service and retention in business-to-business buyer-seller relationships. Journal of business research, 56(4), 323-340.

Kirca, A. H., Jayachandran, S., and Bearden, W. O. (2005). Market orientation: a meta-analytic review and assessment of its antecedents and impact on performance. Journal of Marketing, 69(2), 24-41.

Kohli A andJaworski B (1990). Market orientation: The construct, research propositions, and managerial implications. Journal of Marketing, 54 (2), 1-18.

Kulp, S.C., Lee, H.L. and Ofek, E. (2004), "Manufacturer benefits from information integration with retail customers”, Management Science, Vol. 50, No. 4, pp. 431-44.

Kumar, V., Venkatesan, R., Bohling, T., and Beckmann, D. (2008). Practice prize report-The power of CLV: Managing customer lifetime value at IBM.Marketing Science, 27(4), 585-599.

Lancaster, G and Van der Velden, H, (2004),"The influence of employee characteristics on market orientation", International Journal of Bank Marketing, Vol. 22 Iss 5 pp. 343 - 365

Langerak, F. (2003). An appraisal of research on the predictive power of market orientation. European Management Journal, 21(4), 447-464.

Lussier, B. and Hartmann, N. N. (2016). How psychological resourcefulness increases salesperson's sales performance and the satisfaction of their customers: Exploring the mediating role of customer-oriented behaviors. Industrial Marketing Management.

Leigh, T. W., and Marshall, G. W. (2001). Research priorities in sales strategy and performance. Journal of Personal Selling and Sales Management, 21(2), 83-93.

Macintosh, G. (2007). Customer orientation, relationship quality, and relational benefits to the firm. Journal of Services Marketing, 21(3), 150-159.

Madjar, N., Greenberg, E., and Chen, Z. (2011). Factors for radical creativity, incremental creativity, and routine, noncreative performance. Journal of Applied Psychology, 96(4), 730.

Mael, F. A., andAshforth, B. E. (1995). Loyal from day one: Biodata, organisational identification, and turnover among newcomers. Personnel Psychology, 48(2), 309-333. 
McIntyre, R. P., Claxton, R. P., Anselmi, K., and Wheatley, E. W. (2000). Cognitive style as an antecedent to adaptiveness, customer orientation, and self-perceived selling performance. Journal of Business and Psychology, 15(2), 179-196.

McClure, R. E. (2010). The influence of organisational culture and conflict on market orientation. Journal of Business and Industrial Marketing, 25(7), 514-524.

Mowen, J. C., and Spears, N. (1999). Understanding compulsive buying among college students: A hierarchical approach. Journal of Consumer Psychology, 8(4), 407-430.

Narver, J. and Slater, S. (1994). Does Competitive Environment Moderate the Market Orientation-Performance Relationship? Journal of Marketing, 58, 46-55.

Oliver, R. L., and Anderson, E. (1994). An empirical test of the consequences of behavior-and outcome-based sales control systems. The Journal of Marketing, 53-67.

Padmavathy, C., Balaji, M. S., andSivakumar, V. J. (2012). Measuring effectiveness of customer relationship management in Indian retail banks .International Journal of Bank Marketing, 30(4), 246-266.

Piercy, N. F., Cravens, D. W., and Morgan, N. A. (1998). Salesforce performance and behaviour-based management processes in business-to-business sales organisations. European Journal of Marketing, 32(1/2), 79-100.

Porter, L. W., Steers, R. M., Mowday, R. T., and Boulian, P. V. (1974). Organisational commitment, job satisfaction, and turnover among psychiatric technicians. Journal of applied psychology, 59(5), 603.

Rapp, A., Trainor, K. J., andAgnihotri, R. (2010). Performance implications of customerlinking capabilities: Examining the complementary role of customer orientation and CRM technology. Journal of Business Research, 63(11), 1229-1236.

Salgado, J. F. (1997). The five factor model of personality and job performance in the European Community, Journal of Applied Psychology, Vol. 82, 30-43

Sandvik, I. L., andSandvik, K. (2003). The impact of market orientation on product innovativeness and business performance. International Journal of Research in Marketing, 20(4), 355-376.

Saxe, R andWeitz, B. A. (1982). The SOCO scale: A measure of the customer orientation of salespeople. Journal of Marketing Research. XIX, 341-351

Schmit, M. J., and Allscheid, S. P. (1995). Employee attitudes and customer satisfaction: Making theoretical and empirical connections. Personnel psychology, 48(3), 521-536.

Schwepker Jr, C. H. (2003). Customer-oriented selling: A review, extension, and directions for future research. Journal of Personal Selling and Sales Management, 23(2), 151-171. 
Siguaw, J. A., Brown, G., and Widing, R. E. (1994). The influence of the market orientation of the firm on sales force behavior and attitudes. Journal of marketing research, 106-116.

Singh, S., and Ranchhod, A. (2004). Market orientation and customer satisfaction: Evidence from British machine tool industry. Industrial Marketing Management, 33(2), 135-144.

Stock, R. M., and Hoyer, W. D. (2005). An attitude-behavior model of salespeople's customer orientation. Journal of the academy of marketing science, 33(4), 536-552.

Suleiman Awwad, M., and Mohammad Agti, D. A. (2011). The impact of internal marketing on commercial banks' market orientation. International Journal of Bank Marketing, 29(4), 308-332.

Swenson, M. J., and Herche, J. (1994). Social values and salesperson performance: an empirical examination. Journal of the Academy of Marketing Science, 22(3), 283-289.

Testa, M. R. (2001). Organisational commitment, job satisfaction, and effort in the service environment. The Journal of Psychology, 135(2), 226-236.

Thakor, M. V., and Joshi, A. W. (2005). Motivating salesperson customer orientation: insights from the job characteristics model. Journal of Business Research, 58(5), 584-592.

Tse, A. Sin, L. Yau, O. Lee, J. and Chow, R (2003) "Market Orientation and Business Performance in a Chinese Business Environment". Journal of Business Research. Pp227-239.

Van der Voet, J., Groeneveld, S. M., andKuipers, B. S. (2013). Talking the talk or walking the walk? The leadership of planned and emergent change in a public organisation. Journal of Change Management.

Weeks, W. A., Roberts, J., Chonko, L. B., and Jones, E. (2004). Organisational readiness for change, individual fear of change, and sales manager performance: An empirical investigation. Journal of Personal Selling and Sales Management, 24(1), 7-17.

Widmier, Scott M., Donald W. Jackson, Jr., and Deborah Brown McCabe (2002), "Infusing Technology into Personal Selling, "Journal of Personal Selling and Sales Management, 22, (Summer), 189-198.

Williams, M. R. andAttaway, J. S. (1996). Exploring salespersons' customer orientation as a mediator of organisational culture's influence on buyer-seller relationships. Journal of Personal Selling and Sales Management. XVI, 4: 33-52.

Williams, M. R., and Wiener, J. (1990). Does the selling orientation-customer orientation (SOCO) scale measure behavior or disposition? Enhancing knowledge development in marketing, 239-242.

Yee, R. W., Yeung, A. C., and Cheng, T. E. (2008). The impact of employee satisfaction on quality and profitability in high-contact service industries. Journal of operations management, 26(5), 651-668. 
Zablah, A. R., Franke, G. R., Brown, T. J., and Bartholomew, D. E. (2012). How and when does customer orientation influence frontline employee job outcomes? A meta-analytic evaluation. Journal of Marketing, 76(3), 21-40. 
Table. 2 Inter-construct correlation matrix

\begin{tabular}{|c|c|c|c|c|c|c|c|c|c|c|c|c|c|c|c|}
\hline \multicolumn{14}{|c|}{ Correlations } & \multirow[b]{2}{*}{ Mean } & \multirow[b]{2}{*}{$\begin{array}{c}\text { Std. } \\
\text { Deviation }\end{array}$} \\
\hline & OCO & OC & $\mathrm{OZ}$ & SWE & $\mathrm{EM}$ & OI & PS & SCO & PINS & PAB & PNA & PCON & SP & & \\
\hline Oco & 1 & & & & & & & & & & & & & 6.1986 & 1.00875 \\
\hline OC & $.550^{* *}$ & 1 & & & & & & & & & & & & 5.6365 & 1.25079 \\
\hline $\mathrm{OZ}$ & $-.090^{\star *}$ & $.074^{*}$ & 1 & & & & & & & & & & & 3.6234 & 1.74575 \\
\hline SWE & $.318^{* *}$ & $.326^{* *}$ & $.094^{* *}$ & 1 & & & & & & & & & & 5.3623 & 1.44208 \\
\hline EM & $.522^{* *}$ & $.465^{* *}$ & -.003 & $.350^{* *}$ & 1 & & & & & & & & & 5.9083 & 1.07571 \\
\hline $\mathrm{Ol}$ & $.525^{* *}$ & $.406^{* *}$ & $-.063^{*}$ & $.394^{* *}$ & $.629^{* *}$ & 1 & & & & & & & & 5.9269 & 1.10434 \\
\hline PS & $267^{* *}$ & $.204^{* *}$ & $.121^{\star \star}$ & $.242^{* *}$ & $.383^{* *}$ & $.333^{* *}$ & 1 & & & & & & & 4.9123 & 1.51295 \\
\hline Sco & $.521^{* *}$ & $.412^{* *}$ & $-.098^{* *}$ & $.359^{* *}$ & $.520^{* *}$ & $.581^{* *}$ & $.253^{* *}$ & 1 & & & & & & 6.2371 & .83109 \\
\hline PINS & $-.063^{*}$ & $-.086^{\star *}$ & $.304^{* *}$ & -.044 & -.054 & $-.112^{* *}$ & $.078^{* *}$ & $-.140^{* *}$ & 1 & & & & & 2.9081 & 1.97188 \\
\hline PAB & $.177^{* *}$ & $.193^{* *}$ & -.027 & $.203^{* *}$ & $.219^{* *}$ & $252^{* *}$ & $.067^{*}$ & $.282^{* *}$ & $.075^{\star}$ & 1 & & & & 6.6444 & 2.02237 \\
\hline PNA & $.134^{* *}$ & $.114^{* *}$ & $.085^{* *}$ & $.102^{* *}$ & $.104^{* *}$ & $.142^{* *}$ & $.093^{* *}$ & $.156^{* *}$ & $.163^{* *}$ & $.224^{* *}$ & 1 & & & 6.4304 & 1.92353 \\
\hline PCON & $.190^{* *}$ & $.143^{* *}$ & .044 & $.116^{* *}$ & $.083^{* *}$ & $.184^{* *}$ & $.181^{* *}$ & $.181^{* *}$ & .026 & .049 & $.426^{* *}$ & 1 & & 6.7880 & 1.74390 \\
\hline SP & $.362^{* *}$ & $.372^{* *}$ & .000 & $.307^{* *}$ & $.447^{* *}$ & $.404^{* *}$ & $.220^{* *}$ & $.433^{* *}$ & .039 & $.301^{* \star}$ & $.193^{* *}$ & $.151^{\star *}$ & 1 & 5.5356 & 1.22015 \\
\hline \multicolumn{16}{|c|}{${ }^{*}$. Correlation is significant at the 0.01 level (2-tailed). } \\
\hline Corre & is sig & ant at & $.05 \mathrm{le}$ & -tailed & & & & & & & & & & & \\
\hline
\end{tabular}


Table 1: Details of Critical Considerations regarding Validity

\begin{tabular}{|c|c|c|c|c|c|c|c|c|c|c|c|c|c|c|}
\hline $\begin{array}{l}\text { S } \\
\text { No. }\end{array}$ & Consideration & OCO & OC & $\mathbf{O Z}$ & SWE & EM & OI & PS & PINS & PAB & PNA & PCON & SCO & SP \\
\hline 1 & $\begin{array}{l}\text { Cronbach } \\
\text { alpha } \\
\text { coefficient }\end{array}$ & 0.921 & 0.852 & 0.796 & 0.758 & 0.809 & 0.814 & 0.823 & 0.879 & 0.829 & 0.753 & 0.954 & 0.910 & 0.958 \\
\hline 2 & $\begin{array}{l}\text { Composite } \\
\text { reliability }\end{array}$ & 0.938 & 0.900 & 0.868 & 0.848 & 0.869 & 0.870 & 0.876 & 0.912 & 0.898 & 0.862 & 0.966 & 0.925 & 0.967 \\
\hline 3 & $\begin{array}{l}\text { Average } \\
\text { variance } \\
\text { extracted }\end{array}$ & 0.717 & 0.692 & 0.625 & 0.587 & 0.556 & 0.529 & 0.588 & 0.674 & 0.746 & 0.684 & 0.878 & 0.516 & 0.856 \\
\hline 4 & $\begin{array}{l}\text { Full } \\
\text { Collinearity } \\
\text { VIF }\end{array}$ & 1.898 & 1.641 & 1.193 & 1.328 & 2.202 & 2.448 & 1.356 & 1.207 & 1.201 & 1.328 & 1.308 & 1.876 & 1.365 \\
\hline 5 & $\begin{array}{l}\text { Effect sizes of } \\
\text { path } \\
\text { coefficient } \\
\text { (For paths } \\
\text { ending at SP) }\end{array}$ & 0.013 & 0.049 & 0.007 & 0.020 & 0.091 & 0.010 & 0.011 & 0.028 & 0.026 & 0.010 & 0.003 & 0.059 & NA \\
\hline 6 & $\begin{array}{l}\text { Convergent } \\
\text { validity }\end{array}$ & \multicolumn{13}{|c|}{ Established as all 'p' values $<0.05$; loadings $>0.5$; cross loadings $<0.5$ for reflective measures } \\
\hline 7 & $\begin{array}{l}\text { Discriminant } \\
\text { validity }\end{array}$ & \multicolumn{13}{|c|}{$\begin{array}{l}\text { Established as square root of average variance extracted was found higher than any of the correlations } \\
\text { involving that variable }\end{array}$} \\
\hline 8 & $\begin{array}{l}\text { Predictive } \\
\text { validity }\end{array}$ & \multicolumn{13}{|c|}{ Established a Q-squared coefficient of .465 for SCO and .284 for SP } \\
\hline
\end{tabular}

SCO - salesperson customer orientation; SP - Salesperson Performance; OCO - organisational customer orientation; OC - organisational competitive orientation; OZ- organisational centralisation; SWE - supportive work environment; EM- experienced Meaningfulness; OI organisational Identification; PS-Pay satisfaction; PAB- Agreeability; PNA- Need for activity; PINS - Instability; PCON Conscientiousness 
Organisational

Factors

Job Factors

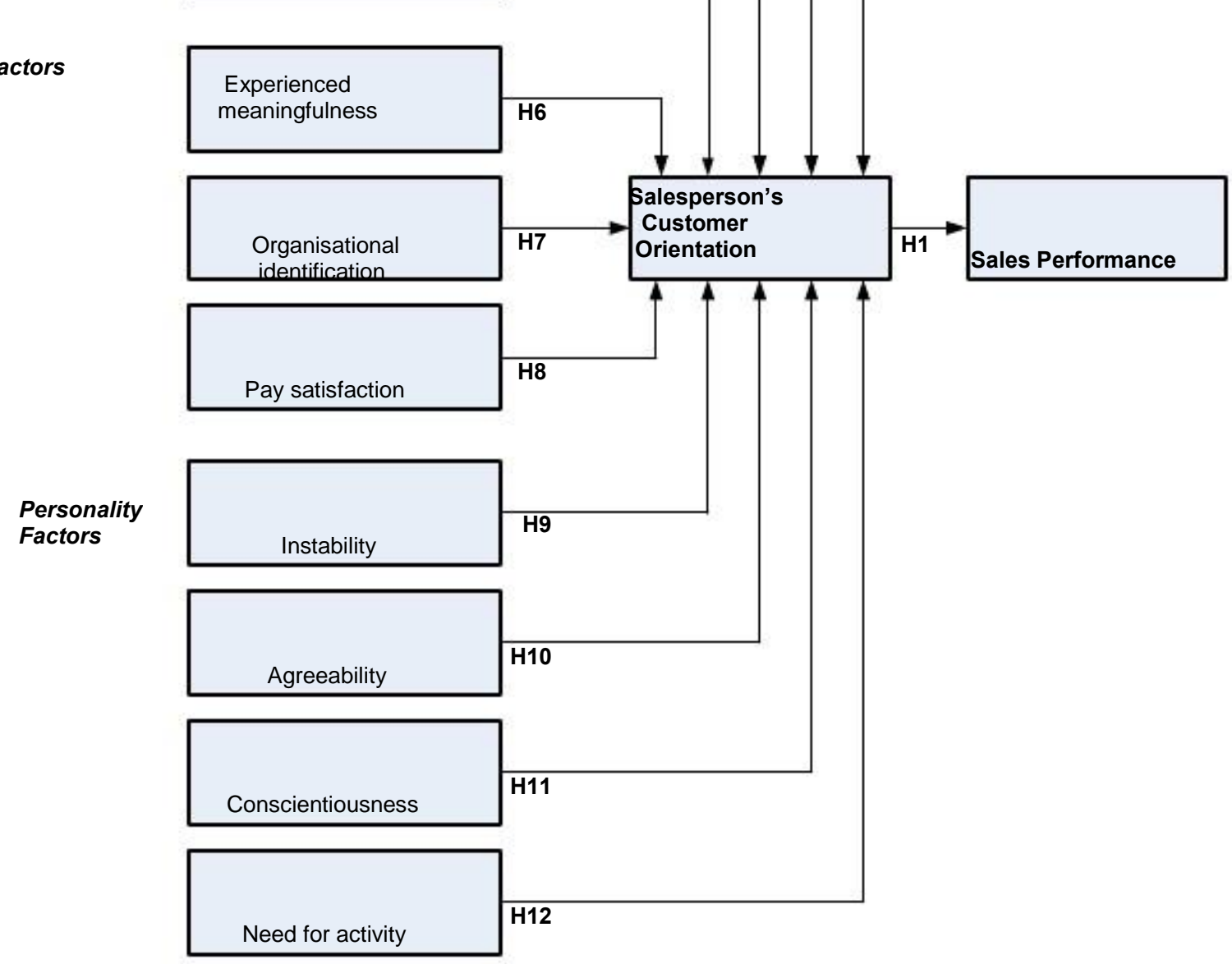

FIGURE 1: The conceptual (fully) mediated model
Organisational customer

\section{H1}

Organisational

competitive orientation

\section{$\mathrm{H} 2$}

H3

Centralisation

Supportive work

environment

H4

Sales Performance orientation 
Organisational Factors
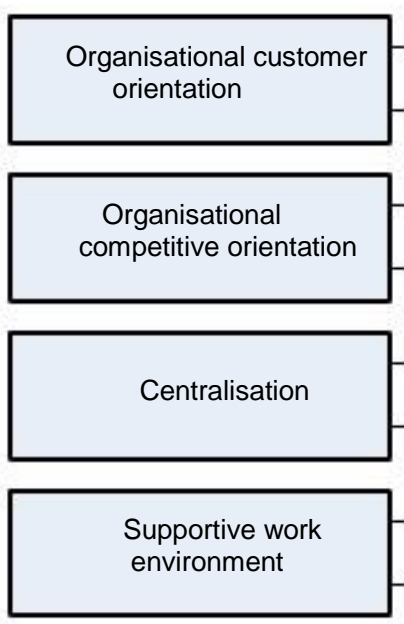

Job Factors
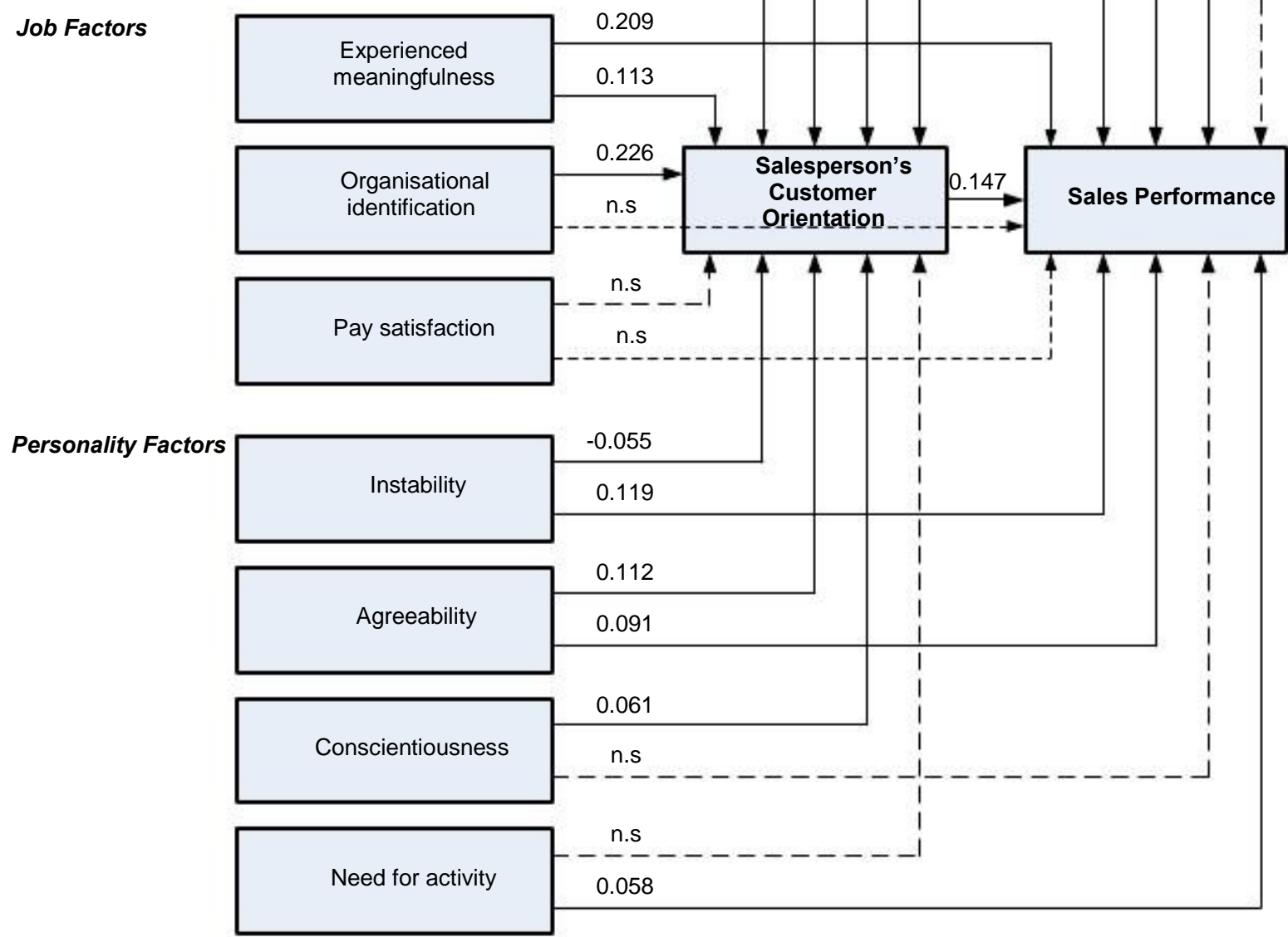

n.s $-------------------7$ 0.198

0.137

0.042

0.500

$-0.116$

0.062

0.052

Pay satisfaction

\begin{tabular}{l}
0.209 \\
\hline 0.11 \\
\hline
\end{tabular}

FIGURE 2: Results of the estimated (partially) mediated model 
Organisational Factors

Job Factors

Personality Factors

Job Factors

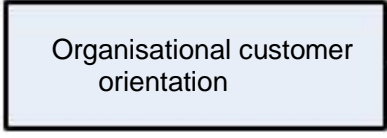

-1 n.s $----------------1$

Organisational competitive orientation

0.144

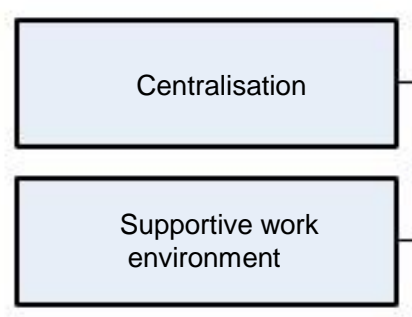
$--\underline{\text { n.s }}$

n.s 0.072

Supportive work

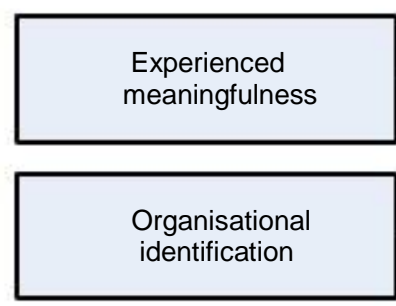

0.226

Pay satisfaction n.s

0.067
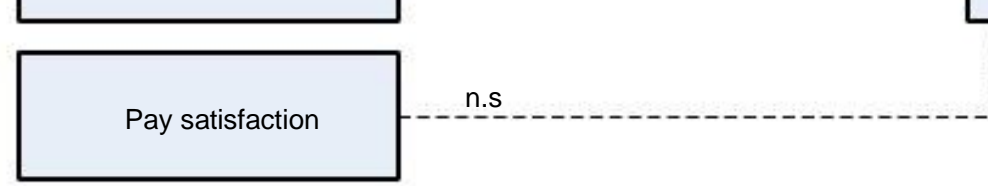

Sales Performance

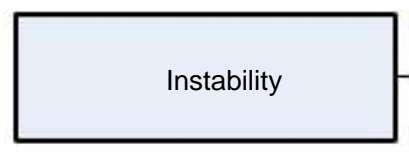

0.114

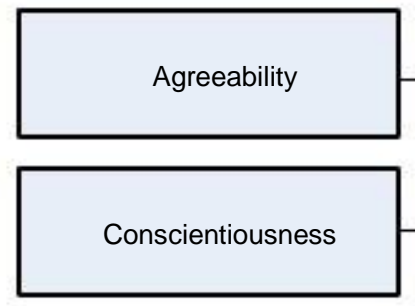

0.111

Need for activity

0.057

FIGURE 3: Results of the estimated non-mediated model 
